\title{
Assessment of prognostic factors in patients undergoing surgery for non-rheumatic mitral regurgitation
}

\author{
S SALTISSI, A CROWTHER, C BYRNE, D J COLTART, B S JENKINS, \\ $M$ M WEBB-PEPLOE
}

From the Department of Cardiology, St Thomas' Hospital, London

SUMMARY Twenty-four patients who had undergone mitral valve surgery for pure non-rheumatic mitral regurgitation were studied non-invasively six months to six years postoperatively. The long-term results of operation were assessed on the basis of clinical history, echocardiography, and treadmill stress testing using a points scoring system. The score so obtained was used to divide the patients into those with a good response to surgery (group 1) and those responding poorly (group 2). The effects on the long-term surgical outcome of several intraoperative and preoperative factors were then analysed both together and separately.

A short symptomatic history ( $<1$ year), a normal left ventricular end-diastolic volume index $\left(\leqslant 100 \mathrm{ml}\right.$ per $\mathrm{m}^{2}$ ), and a large post-ectopic potentiation of $\mathrm{KV} \max \left(>50 \mathrm{~s}^{-1}\right.$ ) were found to be favourable prognostic factors when analysed independently. An angiographic ejection fraction $<0.5$ was uniformly associated with a poor outcome, and 71 per cent of patients in atrial fibrillation at the time of operation also responded badly. In those patients with good long-term function, cold potassium cardioplegia was more commonly used than intermittent aortic cross clamping as the means of intraoperative myocardial preservation, though this difference did not reach conventional significance.

A standard analysis of variance allowed assessment of length of history, left ventricular enddiastolic volume index, and type of valve prosthesis simultaneously. This indicated that both length of history and left ventricular end-diastolic volume index were highly significant prognostic factors. The use of a Björk-Shiley as opposed to a Starr-Edwards prosthesis also emerged as significantly favouring a good long-term result.

The state of the left ventricular myocardium before operation and the type of valve prosthesis used were thus shown to be the prime determinants of surgical outcome in these patients. The optimum time for operation was shown to be within one year of the onset of symptoms, and before the left left ventricular end-diastolic volume index exceeds $100 \mathrm{ml}$ per $\mathrm{m}^{2}$, or the ejection fraction falls to $<0.5$. At such a time, irreversible changes in myocardial function sufficient to negate the beneficial effects of mitral valve surgery have not yet occurred.

The overall mortality and long-term functional capacity after mitral valve replacement have improved considerably since the operation was first performed successfully in $1960 . .^{1}$ Operative mortality has fallen from 18 per cent ${ }^{2}$ to 2 to 5 per cent, with a late mortality of 10 to 16 per cent. ${ }^{34}$ In this hospital, the 30 day mortality for all patients undergoing mitral valve replacement averaged $7 \cdot 2$ per cent from 1976 to 1978 , the period during which the majority of patients in the present Received for publication 31 March 1980 study underwent operation. This improvement in mortality has been the result in the main of advances in intraoperative factors-principally surgical techniques, methods of myocardial preservation, and prosthetic valve design. Mitral valve replacement for pure mitral regurgitation, however, has been substantially less successful than for pure mitral stenosis-20 per cent versus 5 per cent early mortality. ${ }^{5}$ The poor results in these patients are associated with low cardiac output states postoperatively-almost invariably in those with long- 
standing preoperative congestive heart failure and impaired left ventricular function at the time of operation.

Two differing views have been forwarded to explain these unsatisfactory results. Kirklin ${ }^{6}$ has pointed out that the timing of operation depends upon the relative risks of the uncorrected disease versus those of operation and prosthesis combined. The poor outcome of operation until recently has meant that operation has usually been delayed until symptoms were far advanced and refractory to medical treatment. At this stage, impairment of cardiac functional reserve resulting from longstanding regurgitation results in the myocardium being unable to compensate for the increased afterload which accompanies the sudden return of valvular competence by mitral valve replacement. In Kirklin's view, since prognosis is now less influenced by surgical factors, operation ought to be advised earlier as its delay merely results in further myocardial impairment so contributing to operative mortality and chronic incapacity. The alternative view is that the events of prime prognostic importance occur during operation, not before it. ${ }^{\text {? }}$ Thus further improvement in results would be principally dependent upon advances in methods of intraoperative myocardial preservation and valve design.

The purpose of the present study was to assess the influence of (a) intraoperative factors, and (b) the preoperative functional status of the left ventricle as determined by clinical, haemodynamic, and angiographic indices on the long-term surgical outcome of a group of patients with pure nonrheumatic mitral regurgitation. On the basis of the preoperative indices an attempt was made to define criteria which would indicate the optimum time for surgery in such patients.

\section{Subjects and methods}

The study group consisted of 24 patients ( 15 men and nine women) who had survived mitral valve surgery for pure non-rheumatic mitral regurgitation and who consented to further investigation (Table 1). All patients were operated on from 1973 to 1978 and in all cases at least six months and no more than six years had elapsed since operation. A further six patients who fulfilled the inclusion criteria either could not be contacted or refused consent.

All 24 patients had undergone cardiac catheterisation and data from left ventriculography were available in 20 of these. Patients with mitral stenosis or more than trivial disease of other valves were excluded, as were those with clinical or angiographic evidence of coronary artery disease preoperatively. In fact, 16 of the 24 patients had undergone selective coronary angiography and in these no critical lesions ( $>50 \%$ of the luminal diameter) were demonstrated. In the eight patients who did not have coronary angiography, the absence of coronary artery disease was not proven but was assumed on the basis of (i) lack of relevant symptoms and signs either preoperatively or between operation and restudy in all patients, and (ii) lack of wall motion abnormalities on left ventriculography in the four patients who had left ventriculography but not coronary angiography.

All patients underwent non-invasive assessment consisting of the following:

(a) Clinical history and examination-particular attention being paid to symptomatology (New York Heart Association Classification: NYHA) and the degree of subjective improvement since operation. Clinical evidence of prosthetic valve dysfunction or paraprosthetic leak was sought.

(b) M-mode echocardiography-scanning was

Table 1 Operative data and aetiology

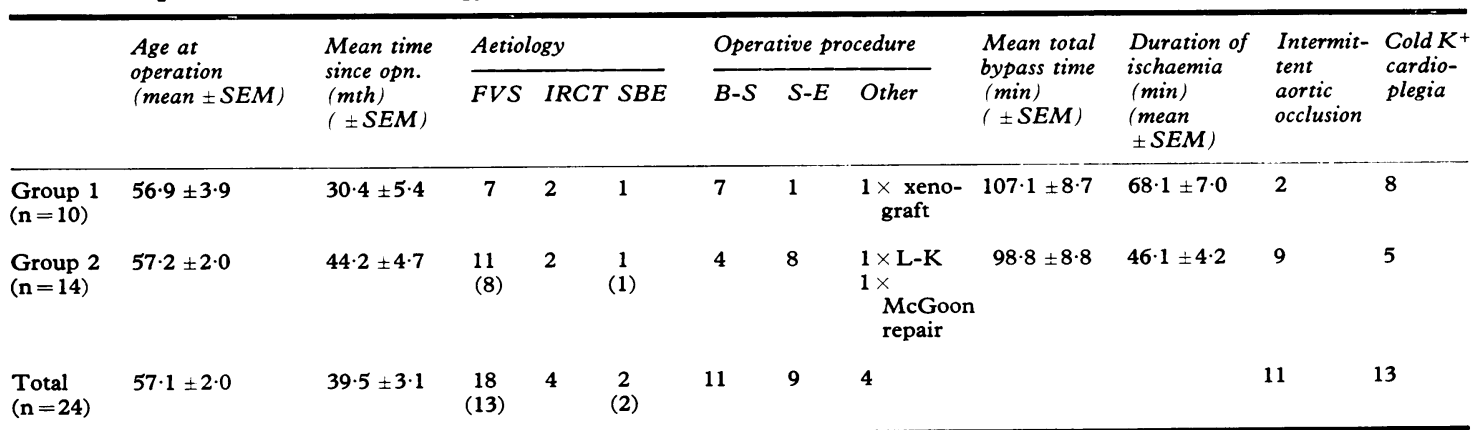

FVS, Floppy valve syndrome; IRCT, idiopathic rupture of chordae tendineae; SBE, subacute bacterial endocarditis; B-S, Björk-Shiley prosthesis; S-E, Starr-Edwards prosthesis; L-K, Lillehei-Kaster prosthesis; SEM, standard error of the mean.

Figures in parentheses refer to the number of patients with ruptured chordae secondary to other pathology. 
carried out using a Smith-Kline Ekoline 20 ultrasonoscope with a $2 \cdot 25 \mathrm{MHz}$ focused transducer. Records were made on photographic paper at speeds of 25 to $100 \mathrm{~mm} / \mathrm{s}$. Echoes from the left side of the interventricular septum and the posterior left ventricular endocardium were first identified with the transducer angled caudally and laterally to a position just below the prosthetic valve echo. In this position, the internal diameter of the left ventricle was measured at the instant of peak inward motion of the posterior wall (systole, LVIDs) and at the electrocardiographic $\mathrm{Q}$ wave (diastole, LVIDd). The fractional shortening per cent (FS \%) and the mean velocity of circumferential fibre shortening (mean $\mathrm{V}_{\mathrm{CF}}$ ) were derived from the following formulae:

$$
\begin{aligned}
& \text { FS } \%=\frac{\text { LVIDd - LVIDs }}{\text { LVIDd }} \times 100 \\
& \text { and mean } \mathrm{V}_{\mathrm{CF}}=\frac{\text { LVIDd - LVIDs }}{\text { LVIDd } \times \mathrm{ET}}
\end{aligned}
$$

where ET is the ejection time in seconds. This was taken as the interval between echocardiographic aortic valve opening and closure. If adequate aortic valve echoes were not observed, then ejection time was measured as the time from onset to peak posterior left ventricular wall motion. ${ }^{8}$

The motion of the prosthetic valve and of the septum was noted and the presence of clot formation sought in order to assess prosthetic valve function and the presence or absence of paraprosthetic leak. ${ }^{9}$

(c) Maximal exercise stress testing-this was performed on an Avionics E16 programmable treadmill. The standard Bruce procedure of continuous three minute exercise stages was carried out and maximal exercise performance was encouraged by adopting a symptomatic end-point of chest pain, dyspnoea, or fatigue. The electrocardiogram was continuously monitored on an Avionics Exerstress 3000 electrocardiograph system and nine lead printout (the six limb leads $+V 4$ to 6 ) obtained towards the end of each stage. The time-intoprocedure achieved was noted and the functional aerobic impairment calculated from a standard nomogram. Maximal heart rate and systolic blood pressure were noted but not incorporated into the functional grading system (see below).

\section{GRADING OF POSTOPERATIVE FUNCTIONAL STATUS}

Since no single index of myocardial function is valid under all circumstances, ${ }^{10}$ a scoring system based on improvement in symptoms (change in
Table 2 Criteria underlying functional grading of

\begin{tabular}{|c|c|c|c|}
\hline \multirow[b]{3}{*}{ NYHA classification } & \multicolumn{3}{|c|}{ Functional score } \\
\hline & 1 & 2 & 3 \\
\hline & $\begin{array}{l}\text { Improvement } \\
\text { by two classes } \\
\text { or to Class } 1\end{array}$ & $\begin{array}{l}\text { Improvement } \\
\text { by one class }\end{array}$ & $\begin{array}{l}\text { No change } \\
\text { in class }\end{array}$ \\
\hline Fractional shortening $(\%)$ & $\geqslant 25$ & $15-24$ & $\leqslant 14$ \\
\hline $\begin{array}{l}\text { Mean circumferential } \\
\text { shortening velocity } \\
(\operatorname{circ} / \mathrm{s})\end{array}$ & $\geqslant 0.9$ & $0.6-0.8$ & $\leqslant 0.5$ \\
\hline Time-into-procedure ( $\mathrm{min}$ ) & $\geqslant 7 \cdot 5$ & $4 \cdot 5-7 \cdot 4$ & $\leqslant 4 \cdot 4$ \\
\hline $\begin{array}{c}\text { Functional aerobic } \\
\text { impairment }(\%)\end{array}$ & $\leqslant 13$ & $14-26$ & $\geqslant 27$ \\
\hline
\end{tabular}
postoperative status

Group 1 (good functional status) $=$ total score $\leqslant 8$.

Group 2 (poor functional status) $=$ total score $\geqslant 9$.

NYHA class), echocardiographic measurements (mean $\mathrm{V}_{\mathrm{CF}}$ and $\mathrm{FS} \%$ ), and the results of exercise testing (time-into-procedure; and functional aerobic impairment) was devised. Table 2 indicates the values for each of the five variables which were taken to indicate normal (score 1), mildly impaired (score 2), or grossly impaired (score 3 ) results. The final score reflecting functional status at restudy was obtained by adding up the individual scores for all five variables. For most analyses we considered the patients in two groups: group 1 (total score $\leqslant 8$ ) with good functional capacity indicating a satisfactory response to surgery and group 2 (total score $\geqslant 9$ ) with impaired functional status in keeping with an unsatisfactory outcome.

\section{ASSESSMENT OF PREOPERATIVE STATUS}

Data were obtained from each patient's hospital records, operation notes, and cardiac catheterisation report. The following were considered.

(a) Clinical-NYHA grading of dyspnoea; the duration of dyspnoea; and the preoperative cardiac rhythm.

(b) Haemodynamic - the maximum and minimum values of the first derivative of the high fidelity Telco or Millar micromanometer pressure recordings ( $\max$ and $\min \mathrm{dP} / \mathrm{dt}$ ) obtained by electrical differentiation. These were noted at rest and after an ectopic beat.

- The maximum velocity of contractile element

shortening $\times$ a stiffness constant ( $\mathrm{KV}$ max).

The values at rest and after an ectopic beat were derived using the micromanometer tracings from a plot of

$$
\log \frac{\mathrm{d} \text { Developed pressure }}{\mathrm{dt}}
$$


against pressure, ${ }^{11}$ by an electronic processor. ${ }^{12}$ The post-ectopic potentiation was calculated by subtraction.

- Cardiac index (CI) calculated as

$$
\frac{\text { cardiac output (green dye) }}{\text { body surface area }}
$$

-Stroke volume index (SVI) calculated as

$$
\frac{\mathrm{CI}}{\text { heart rate }}
$$

-Pulmonary vascular resistance (PVR) calculated as:

Mean pulmonary artery pressure - mean wedge pressure

Cardiac output (green dye)

(c) Angiographic-the left ventricular cineangiogram in the right anterior oblique projection was used for analysis. A computerised light pen system enabled the left ventricular end-diastolic volume index, stroke volume index, ejection fraction (EF), and peak $\mathrm{V}_{\mathrm{CF}}$ to be derived. The percentage regurgitant volume $(\% \mathrm{RV})$ was calculated as :

angiographic cardiac output - green dye cardiac output

angiographic cardiac output $\times 100$

\section{OPERATIVE DETAILS (Table 1)}

Mitral regurgitation was corrected surgically by McGoon mitral valve repair in one patient (case 21), while the remaining 23 patients had mitral valve replacement. Of these, 11 had Björk-Shiley disc prostheses, nine had Starr-Edwards (models 6320 and 6400 ball and cage prostheses), and three had other types of artificial valve (detailed in Table 1). The choice of prosthetic valve type was based on the surgical preference current at that time and no selection on the basis of preoperative left ventricular function, left ventricular dimension, or severity of mitral regurgitation was made.

With a single exception, the type of intraoperative myocardial preservation used fell into one of two regimens-either (i) mild systemic hypothermia ( 30 to $32^{\circ} \mathrm{C}$ ) with intermittent aortic cross-clamping to produce ischaemic arrest (11 cases), or (ii) mild systemic hypothermia with cold potassium cardioplegia using St. Thomas' Hospital solution (1 litre of $4^{\circ} \mathrm{C}$ Ringer's solution containing $16 \mathrm{mmol}$ potassium chloride, $16 \mathrm{mmol}$ magnesium chloride, and $1 \mathrm{mmol}$ procaine) infused into the aortic root below the clamp over two to three minutes (13 cases). With this regimen topical profound cardiac cooling was used by running Hartmann's solution at $4^{\circ} \mathrm{C}$ through the pericardium. The one exception (case 9) had cold cardioplegia in an identical manner, but with coronary infusion of ordinary $4^{\circ} \mathrm{C}$ Ringer's solution in place of St. Thomas' Hospital solution.

\section{Statistical analysis}

Initially the results were analysed by Student's $t$ test (paired when appropriate) for small sample sizes or by $\chi^{2}$ test with Yates' correction for small samples. Analysis of individual factors in this way, however, does not take into account the effect of interaction between the different indices. In order to do this, the functional score was used as the "response" variable and a standard analysis of variance approach ${ }^{13}$ adopted. This was effected by means of a "generalised linear model" fitting program called GLIM available on the University of London computer. This program, however, assumes that the scores have an underlying Gaussian distribution. Since such an assumption is not necessarily valid, the response variable was turned into a dichotomy by dividing the results into two groups (group 1 with a good response and group 2 with a poor response to surgery). In view of the relatively small numbers of patients in the study such a dichotomy resulted in there being insufficient data to analyse more than three factors simultaneously.

In the GLIM program a model incorporating the chosen factors is fitted to the given data. Each factor is then excluded in turn and any worsening of the fit between the remaining model and the data is assessed. In this way, the effect of each factor may be analysed having allowed for all others.

To obtain maximum information the results were analysed by all three approaches.

\section{Results}

The clinical, echocardiographic, and stress test results are shown in Table 3, together with the appropriate functional score for each index. Group 1 consists of those patients with a total score $\leqslant 8$ and represents a good response to operation. Group 2 patients had a total score $\geqslant 9$ indicating poor postoperative functional status. In none of the patients studied was there clinical or echocardiographic evidence of prosthetic valve dysfunction, clot formation, or paraprosthetic leak.

The results are presented in three sections. In section A statistical analysis is by standard $\chi^{2}$ and $t$ tests; in section B analysis is by GLIM on the ungrouped data; and in section C by GLIM on the dichotomised data. 


\section{SECTION A}

\section{(1) Clinical data}

(a) Symptomatology: all 24 patients studied were symptomatic when operated on, 13 having Class II (NYHA) dyspnoea and 11 Class III preoperatively. The degree of symptoms and limitation of physical working capacity as judged by the NYHA classification were similar in the two groups. This index was hence not predictive of surgical response for an individual or either group as a whole. After operation, seven patients (29\%) failed to improve their grading at all-the remaining 17 (71\%) improving by at least one grade. Three patients $(12.8 \%)$ improved by two clinical grades.

(b) Atrial fibrillation: 12 out of 17 patients $(71 \%)$ with atrial fibrillation at the time of operation responded poorly (group 2) whereas of the patients in sinus rhythm only two out of seven $(29 \%)$ did badly. Though this difference did not reach conventional significance $(p>0 \cdot 1)$ a trend was apparent (see section B).

(c) Restudy interval: the mean time between operation and restudy for all patients was $39 \cdot 5 \pm 3 \cdot 1$ months. There was no significant difference ( $p>0.05$ ) between the mean for group 1 (30.4 \pm 5.4 months) and that for group 2 ( $44 \cdot 2 \pm 4 \cdot 7$ months).

(d) Age at operation: the age range was from 29 to 71 years (mean $57 \cdot 1 \pm 2 \cdot 0$ years) with the majority in their early 60 s. No significant difference $(p>0 \cdot 1)$ between the mean ages for group 1 $(56.9 \pm 3.9$ years $)$ and group $2(57 \cdot 2 \pm 2 \cdot 0$ years $)$ was found.

\section{(2) Length of history (Fig. 1)}

The duration of the presenting symptoms varied considerably from two months to 16 years. The mean for all 24 patients was 32.0 months \pm 8.7 . In group 1 the mean duration of symptoms before operation was $10 \cdot 2 \pm 12 \cdot 3$ months which was significantly shorter $(p<0.05)$ than for group 2 $(47 \cdot 6 \pm 10 \cdot 4)$. Fig. 1 also shows that eight out of 10 $(80 \%)$ patients in group 1 had symptomatic histories shorter than one year while 11 out of 14 $(79 \%)$ of group 2 complained of symptoms for one year or more before surgery.

\section{(3) Left ventricular end-diastolic volume index}

(Fig. 2)

The mean left ventricular end-diastolic volume index $\left(\mathrm{ml} / \mathrm{m}^{2}\right)$ (calculated as left ventricular end-diastolic volume $\mathrm{ml} /$ body surface area $\mathrm{m}^{2}$ ) for group 1 was $94 \cdot 1 \pm 12 \cdot 2 \mathrm{ml} / \mathrm{m}^{2}$ and that for group 2 was $146 \cdot 4 \pm$ $11 \cdot 1 \mathrm{ml} / \mathrm{m}^{2}$. The difference was highly significant $(\mathrm{p}<0.01)$. In addition, Fig. 2 indicates that seven out of nine $(78 \%)$ group 1 patients on whom angiographic data were available had an index of $100 \mathrm{ml} /$

Table 3 Postoperative clinical, exercise, and echocardiographic data

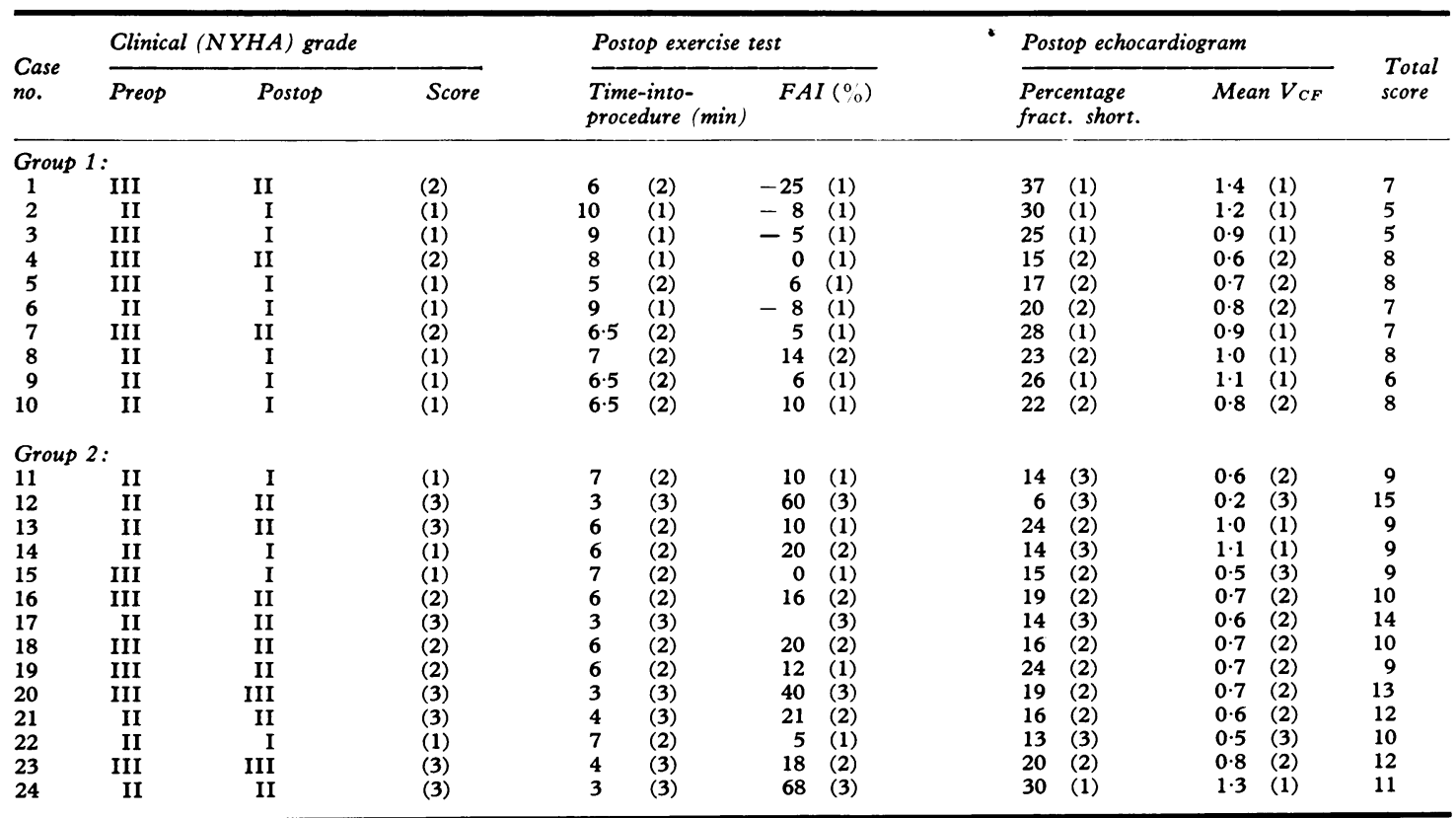

Figures in parentheses represent the functional score for individual variables.

Case 21 underwent mitral valve repair-all others had mitral valve replacement. 
$\mathrm{m}^{2}$ or less. In contrast, all 11 patients (100\%) with angiographic data in group 2 had an index exceeding $100 \mathrm{ml} / \mathrm{m}^{2}$.

(4) Combination of left ventricular end-diastolic volume index and length of history (Fig. 3)

The combination of an index equal to or larger than $100 \mathrm{ml} / \mathrm{m}^{2}$ and a length of history greater than one year (the critical values differentiating group 1 from group 2) defined a subgroup of nine patients all of whom responded poorly to surgery. This combination of critical variables thus proved a highly specific predictor of unsatisfactory surgical response.

(5) Other angiographic variables

(a) Ejection fraction: the mean preoperative ejection fraction did not differ significantly $(p>0 \cdot 1)$ between group $1(0.65 \pm 0.04)$ and group $2(0.55 \pm 0.05)$ (Fig. 4). Of interest, however, was the finding that all three patients with an ejection fraction $<0.5$ responded poorly to surgery. In group 1 the mean

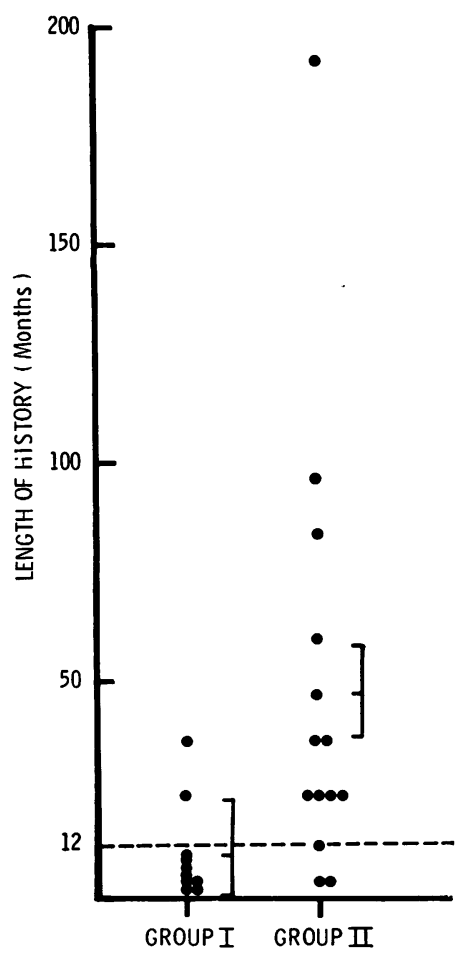

Fig. 1 Duration of symptomatic history according to satisfactory (group 1) or unsatisfactory (group 2) functional capacity at follow-up. The means and standard errors of the means are displayed and the critical time of one year indicated. (See text.)

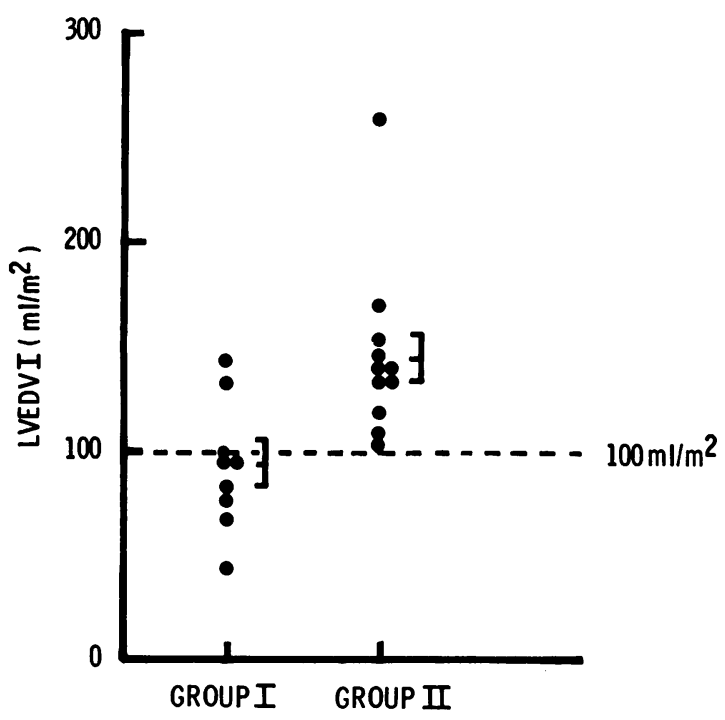

Fig. 2 Comparison between left ventricular end-diastolic volume index (LVEDVI) in those patients responding well (group 1) and those responding poorly (group 2) to mitral valve surgery. The critical left ventricular enddiastolic volume index $\left(100 \mathrm{ml} / \mathrm{m}^{2}\right)$, group means, and SEMs are indicated.

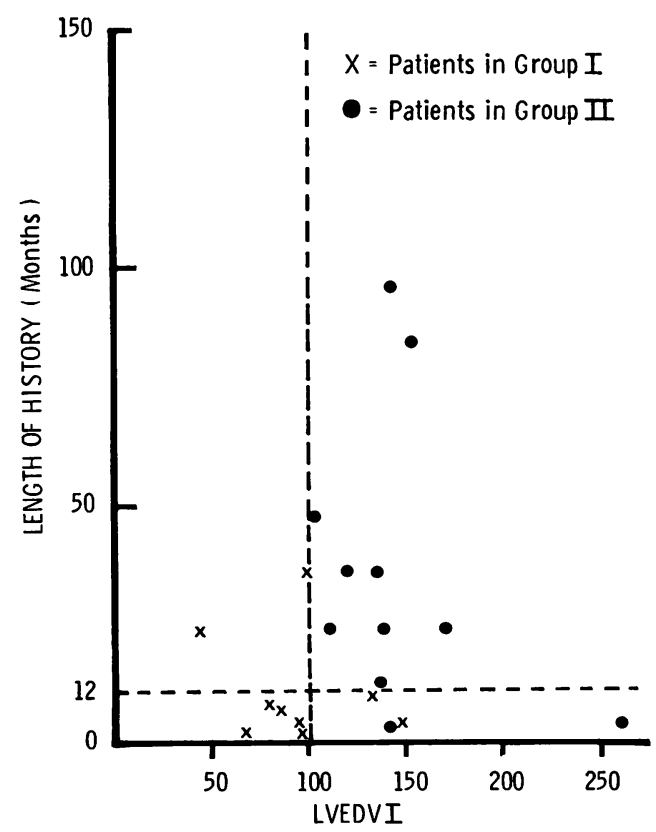

Fig. 3 Graph showing use of the critical values for length of history and LVEDVI in combination to define a subgroup of patients all of whom respond poorly in the long-term to mitral valve surgery (group 2). 
preoperative (angiographic) ejection fraction (0.65 $\pm 0.04)$ fell significantly $(\mathrm{p}<0.01)$ after correction of mitral regurgitation to a mean postoperative (echocardiographic) ejection fraction of $0.47 \pm 0.04$. Similarly, in group 2 the preoperative (angiographic) ejection fraction fell significantly $(p<0.05)$ from $0.55 \pm 0.05$ to $0.40 \pm 0.04$ postoperatively (Fig. 5). These drops in ejection fraction after operation did not differ significantly $(p>0.5)$ between the two groups.

(b) No significant difference between the two groups was found on the basis of preoperative angiographic peak circumferential shortening velocity $\left(\mathbf{V}_{\mathbf{C F}}\right)$, percentage regurgitant volume $(\% \mathrm{RV})$, cardiac index, or stroke volume index. Comparison of preoperative (angiographic) peak $\mathrm{V}_{\text {CF }}$ with postoperative (echocardiographic) mean $V_{\text {CF }}$ showed a significant reduction after operation in both groups of patients (Fig. 6). This reduction was equally significant in patients with good and poor surgical results $(p>1.0$ for unpaired Student's $t$ test comparing changes in $V_{C F}$ after surgery in the two groups).

(6) Haemodynamic data

(a) KV max: neither the resting value nor the

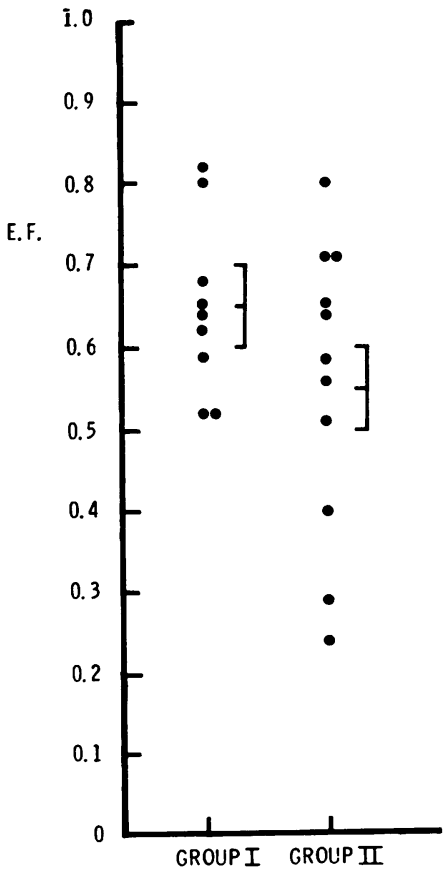

Fig. 4 Comparison of ejection fraction between patients with a satisfactory (group 1) or unsatisfactory (group 2) response to operation. The group means and SEMs are indicated.

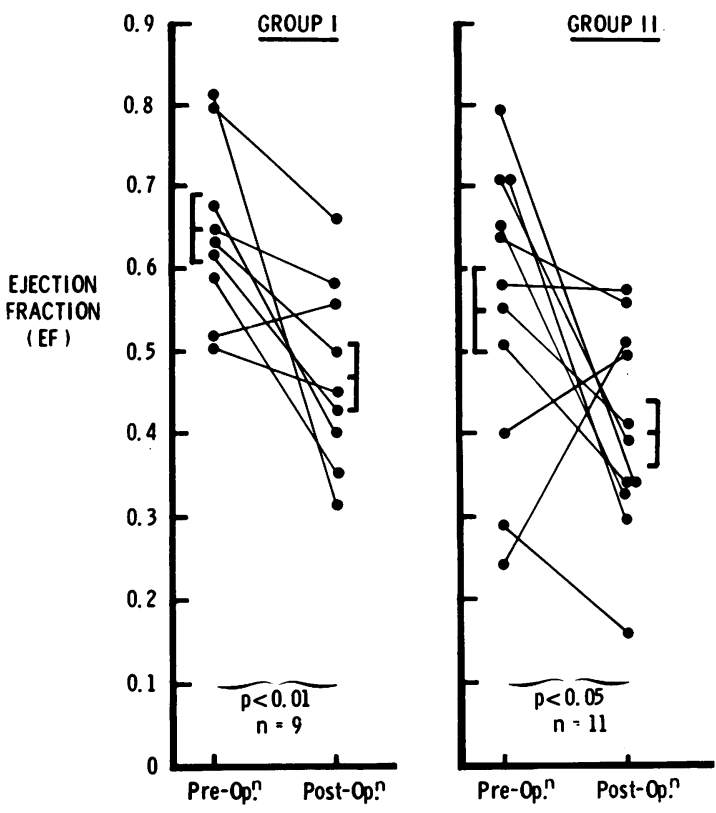

Fig. 5 Change in ejection fraction after correction of mitral regurgitation in patients responding well (group 1) and poorly (group 2) to operation. Note that the preoperative ejection fractions are angiographic and that those postoperatively are echocardiographic. $P$ values refer to the paired Student's $t$ test. Means and SEMs are indicated.

post-ectopic value differed between the two groups. However, the mean post-ectopic potentiation of KV max was significantly greater $(p<0.05)$ in group $1(87 \cdot 4 \pm 19 \cdot 8 / \mathrm{s})$ than in group $2(33 \cdot 4 \pm 14 \cdot 0 / \mathrm{s})$ (Fig. 7).

(b) $\mathrm{dP} / \mathrm{dt}$ : neither the pre- nor the post-ectopic value of the $\max$ (or $\mathrm{min}$ ) $\mathrm{dP} / \mathrm{dt}$ differed significantly between the two groups.

(c) Cardiac index (green dye), stroke volume index, and pulmonary vascular resistance did not differ significantly between the groups.

(7) Type of valve prosthesis

Seven of the 11 patients (64\%) who had a BjörkShiley prosthesis responded well to surgery (group 1) whereas only one out of nine $(11 \%)$ of those with a Starr-Edwards prosthesis did well postoperatively $(p<0.06)$. Those patients receiving a Björk-Shiley prosthesis, however, had a significantly smaller $(p<0.05)$ preoperative mean left ventricular end-diastolic volume index $(104.6 \pm 10.6$ $\mathrm{ml} / \mathrm{m}^{2}$ ) than those receiving a Starr-Edwards prosthesis $\left(152.4 \pm 20.4 \mathrm{ml} / \mathrm{m}^{2}\right)$. Other variables of preoperative left ventricular function were no different between the groups (Table 4). 
Fig. 6 Change in $V_{C F}$ after correction of mitral regurgitation in patients responding well (group 1) and poorly (group 2) to operation. Note that the preoperative values are peak $V_{C F}$ s on angiography and the postoperative ones are mean $V_{C F} S$ on echocardiography. $P$ values refer to the paired Student's $t$ test. Means and SEMs are indicated.
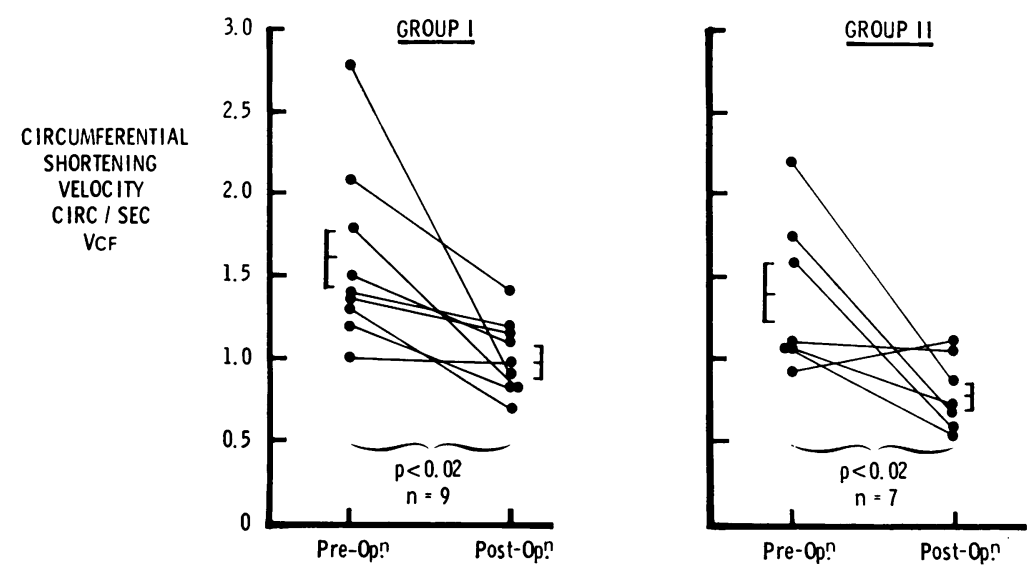

$68.1 \pm 7.0 \mathrm{~min}$ which was in fact longer $(\mathrm{p}>0.05)$ than that in group $2(46 \cdot 1 \pm 4 \cdot 2 \mathrm{~min})$.

(10) Total bypass time

The mean duration of total bypass was 107.1 $\pm 8.7 \mathrm{~min}$ in group 1 which did not differ signi-

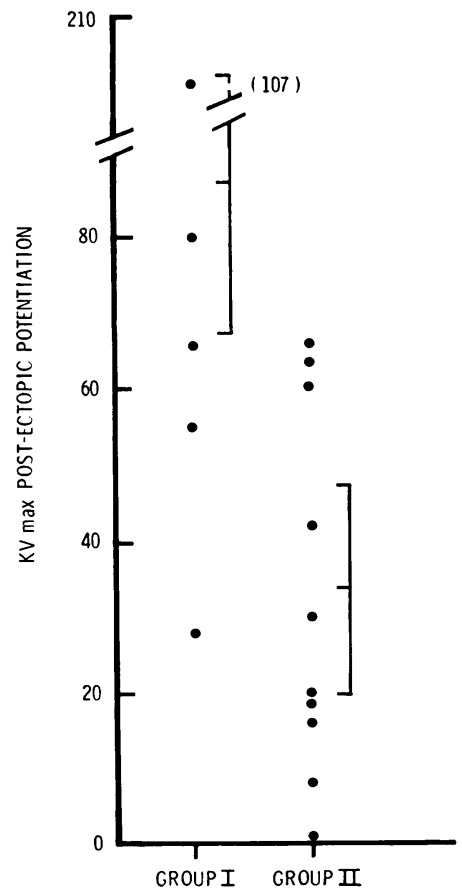

Fig. 7 Post-ectopic potentiation of $K V$ max according to satisfactory (group 1) or unsatisfactory (group 2) response to operation. The group means and SEMs are indicated. 
ficantly $(p>0.05)$ from that in group $2(98.8 \pm 8.8$ $\min )$.

\section{SECTION B}

GLIM analysis of ungrouped data assuming Gaussian distribution again showed a significant effect caused by the length of symptomatic history $(p=0.022)$ when allowance for all other factors was made. The influence of preoperative atrial fibrillation $(p<0.064)$ and of the type of valve prosthesis $(p<0.084)$ was very little short of conventional significance. Other factors analysed in this way showed no significant effects.

\section{SECTION C}

Analysis of the grouped data by GLIM allowed simultaneous assessment of any three factors. Length of history, left ventricular end-diastolic volume index, and type of valve prosthesis were the variables included in the model. By exclusion of each in turn, the effect of any one could be gauged allowing for the influence of the other two (but not, of course, for variables not included in the model, for example presence of atrial fibrillation, type of myocardial preservation, etc.). Analysed in this way, length of history $(p<0.001)$, left ventricular enddiastolic volume index $(p<0.001)$, and type of prosthesis $(p<0.01)$ were all significant in determining long-term postoperative function. Thus, it is apparent that the effects of the length of history and of left ventricular end-diastolic volume index become more significant when allowance is made for other factors in the model. Similarly, type of valve (Björk-Shiley versus Starr-Edwards), which was on the borderline of conventional significance on standard $\chi^{2}$ testing, is shown as being a significant variable when allowance is made for length of history and left ventricular end-diastolic volume index.

\section{Discussion}

The haemodynamic consequences of significant mitral regurgitation result from two mechanisms. Firstly, a volume overload (increased preload) is presented to the left ventricle which requires an increase in total left ventricular stroke work and hence increased myocardial oxygen consumption $\left(\mathrm{MVO}_{2}\right)$. Secondly, the onset of mitral regurgitation reduces the overall impedance to left ventricular emptying by providing a low impedance outlet (left atrium) in parallel with the systemic circuit. The resulting decrease in afterload permits left ventricular contractile activity to be manifest as enhanced velocity and extent of fibre shortening, rather than as wall tension development. ${ }^{14}$ This is closely analogous with isolated muscle experiments which show developed tension to be inversely related to fibre shortening. ${ }^{15}$ These changes may be reflected clinically, as enhanced total (angiographic) left ventricular output, ejection fraction, and $V_{\text {CF }}$. Systolic left ventricular pressure also tends to decline more rapidly for an equivalent amount of preload, and, since peak left ventricular and aortic pressures are not significantly altered, integrated left ventricular wall tension (a major determinant of myocardial $\mathrm{O}_{2}$ consumption) declines more rapidly than normal. ${ }^{14}$ The net effect is a stressed left ventricle with increased work load though, initially at least, the increased total stroke volume is expelled relatively efficiently since a greater portion of myocardial oxygen consumption is spent on muscle shortening than on tension development.

A myocardium with good contractile function copes with this stress adequately for a time, but as its inotropic reserve is exhausted compensatory mechanisms become essential to maintain functionprincipally progressive left ventricular dilatation and eccentric hypertrophy ${ }^{16}$; heterometric autoregulation (Frank-Starling effect); and a decrease in elastic modulus. ${ }^{17}$ An enlarging left ventricle would thus signify impaired contractility and an increasing inability to cope with the stress of mitral regurgitation. In the present study, this has been borne out by the significantly larger mean left ventricular end-diastolic volume index preoperatively in those patients who had unsatisfactory long-term results from operation $(146 \cdot 4 \pm 11 \cdot 1$ $\left.\mathrm{ml} / \mathrm{m}^{2}\right)$ than in those responding well $(94 \cdot 1 \pm 12 \cdot 2$ $\mathrm{ml} / \mathrm{m}^{2}$ ). Indeed, 78 per cent in group 1 had a left ventricular end-diastolic volume index $\leqslant 100 \mathrm{ml} / \mathrm{m}^{2}$, while 100 per cent in group 2 had an index greater than $100 \mathrm{ml} / \mathrm{m}^{2}$ implying that this level is critical. An index within the normal range thus indicates a myocardium which is coping well with the increased workload. Values greater than $100 \mathrm{ml} / \mathrm{m}^{2}$ mean that left ventricular dilatation has occurred to compensate for impaired functional reserve and this is associated with poor long-term surgical results (group 2). The adverse prognostic significance of a large left ventricle found in this study is in close agreement with a recent report that patients with a large rise in pre-mitral valve replacement echocardiographic end-diastolic dimensions undergo progressive deterioration of left ventricular function at long-term follow-up. ${ }^{18}$

The duration of significant mitral regurgitation, as reflected by the length of symptomatic history, was also found to be of prognostic importance. This concurs with the work of Bonchek et al. ${ }^{3}$ whose prognostic index (a combination of duration of 
disabling symptoms and response to medical therapy) proved to be the best of 19 preoperative variables at predicting postoperative improvement. In our study, the history was significantly shorter in group 1 (mean 10.2 \pm 12.3 months) than in group 2 (mean $47.6 \pm 10.4$ months). When symptomatic mitral regurgitation was present for one year or more before operation, 79 per cent had a poor outcome, whereas 80 per cent of patients with shorter histories did well. It thus appears that the longer the symptomatic mitral regurgitation is present, the greater is the risk of myocardial impairment and thus of reduced benefit from surgery. One year was found to be the critical time when such changes become apparent indicating that surgery is optimally timed before this.

Simultaneous consideration of left ventricular end-diastolic volume index $\left(>100 \mathrm{ml} / \mathrm{m}^{2}\right)$ and length of history ( $>1$ year) defined a small subgroup of patients who universally responded badly to operation (Fig. 3). This combined index was more specific than either alone.

The only haemodynamic factor differing significantly $(0.02<p<0.05)$ between the two groups was the post-ectopic potentiation of $\mathrm{KV}$ max80 per cent of group 1 showing rises $>50 / \mathrm{s}$ while 70 per cent of group 2 had values $<50 / \mathrm{s}$. The lower values in group 2 might reflect loss of left ventricular function and indicate that the optimum time for surgery had passed. These findings, however, need interpreting with caution since (a) sample sizes were small, (b) one patient in group 1 (case 10) had an extremely large potentiation which would tend to have an inordinate effect on the group mean, and (c) measurements were made during beats of greatly varying $R R$ interval since many patients were in atrial fibrillation at the time of catheterisation. In fact more patients in group 2 $(12: 86 \%)$ were in atrial fibrillation at the time of operation than in group $1(5: 50 \%)(p>0 \cdot 1)$. Atrial fibrillation thus seemed to be associated with a worse long-term result from mitral valve replacement-possibly reflecting longstanding mitral regurgitation with left atrial enlargement. Conventional significance was not reached but a definite trend was apparent.

The angiographic ejection fraction is a commonly used index of left ventricular function having some predictive value in valvular heart disease. ${ }^{19}$ In the presence of altered loading conditions, however, its usefulness is limited. ${ }^{20}$ In mitral regurgitation, the ejection fraction and other ejection phase indices (including peak $V_{C F}$ ) may be normal but in many cases are supranormal-thus a value in the normal range may, in fact, reflect impaired contractility. This was underlined in the present study by the fact that both the ejection fraction and $V_{C F}$ fell significantly in both groups 1 and 2 after surgical correction of mitral regurgitation (Fig. 5 and 6). It should be noted, however, that the comparisons are between angiographic (preoperative) and echocardiographic (postoperative) data and in the case of $\mathrm{V}_{\mathrm{CF}}$ the comparison is between peak (preoperative) and mean (postoperative) values. None the less, these results imply that the presence of significant mitral regurgitation raises the ejection fraction and $V_{C F}$ in ventricles with both good and bad contractile function.

In the present study, many patients with reduced myocardial function had "normal" values for these indices and no mean difference between the groups emerged. Notably, however, no patient in group 1 had an ejection fraction $<0.5$-all three such patients being in the poor outcome group 2. This indicates that in the presence of significant mitral regurgitation, an ejection fraction $<0.5$ is frankly abnormal, appreciable loss of myocardial contractility must have occurred, and a poor long-term surgical result is likely-again in agreement with the echocardiographic findings of Schuler et al. ${ }^{18}$

In addition to the variables outlined above which define the preoperative conditions of the left ventricle, several intraoperative variables were found to be independently important in determining surgical outcome. In this small series, those patients who received a Björk-Shiley low profile tilting disc prosthesis did significantly better than those with a Starr-Edwards valve when analysed independently of the effects of left ventricular volume and length of history. It should be noted, however, that the Starr-Edwards group was non-homogeneous, incorporating models 6320 (cloth-covered, composite seat, stellite ball) and 6400 (additional stellite track on the inside of each strut). Advantages claimed for the Björk-Shiley prosthesis include improved haemodynamics because of its low profile and a large orifice-to-tissue-diameter ratio also enabling its use in small hearts. These may be relevant to the present finding of greater improvement in longterm functional ability after its use. Those patients receiving a Björk-Shiley prosthesis had a significantly smaller $(p<0.05)$ mean preoperative left ventricular end-diastolic volume index $\left(104.6 \pm 10.6 \mathrm{ml} / \mathrm{m}^{2}\right)$ than those getting a Starr-Edwards valve $(152 \cdot 4 \pm$ 20.4). Though this finding may imply that the Björk-Shiley group had better preoperative left ventricular function, it does not explain the significantly improved results using this valve since the effects of left ventricular end-diastolic volume index were allowed for in the analysis of variance. Also of note is the fact that other indices of left ventricular function (Table 4) not included in the 


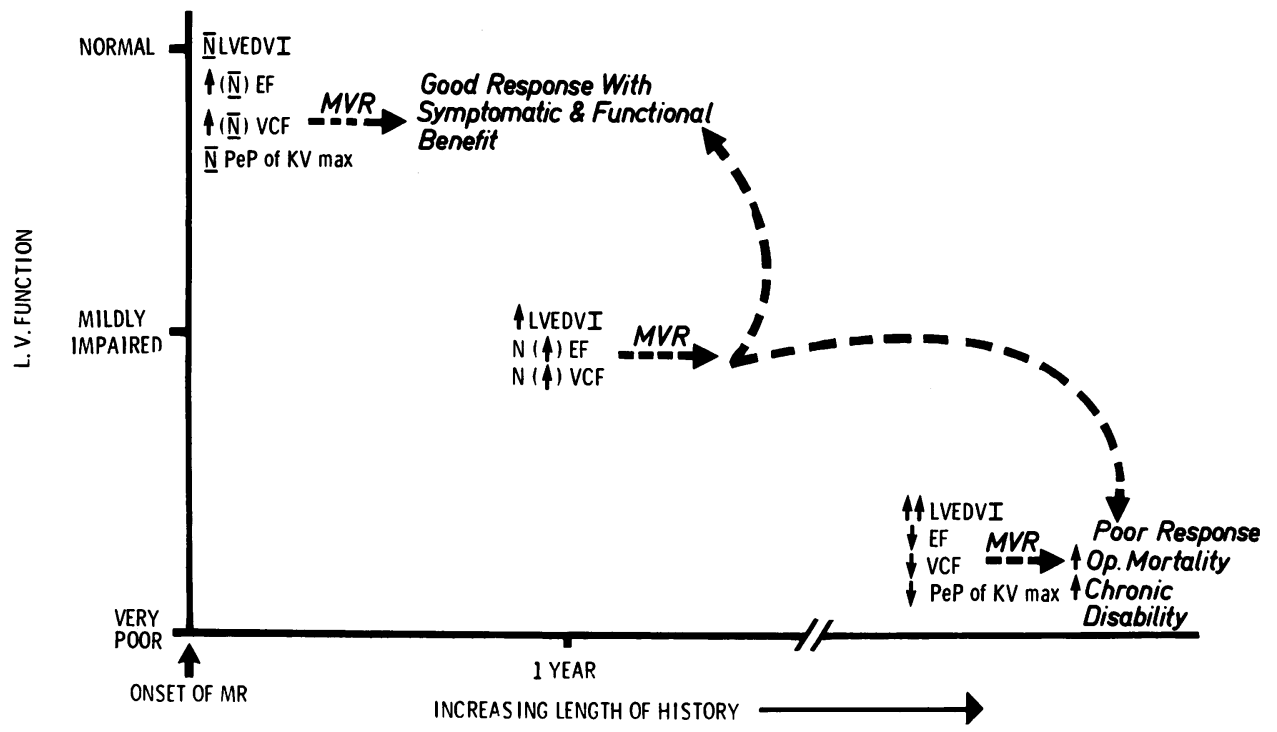

Fig. 8 Diagrammatic representation of the effect of long-standing significant mitral regurgitation on left ventricular function. The changes in preoperative variables with time are shown and the probable response to mitral valve replacement is indicated.

analysis of variance model did not differ between those receiving Björk-Shiley and those receiving Starr-Edwards prosthesis.

Those patients receiving cold potassium cardioplegia with St. Thomas' Hospital solution did somewhat better than those undergoing intermittent aortic cross clamping though the difference was not significant on the numbers studied. The former group, however, may have had more impaired preoperative left ventricular function as indicated by a larger mean left ventricular end-diastolic volume index-a finding that might explain their worse results.

Hence, the results of this study support the concepts that in the presence of significant nonrheumatic mitral regurgitation, the contractile state of the left ventricular myocardium at the time of mitral valve operation and the design of the prosthetic valve inserted are the prime determinants of the surgical outcome, and that progressive impairment of contractility is consequent upon longstanding uncorrected disease (Fig. 8). It thus appears that no benefit accrues from withholding surgery once symptoms have appeared or the left ventricle has begun to dilate and that further delay is deleterious, merely allowing progressive left ventricular impairment.

We would like to thank A V Swan, Department of Community Medicine, St. Thomas' Hospital, for his invaluable help with statistical analysis.

\section{References}

1 Starr A, Edwards ML. Mitral replacement: clinical experience with a ball-valve prosthesis. Ann Surg 1961; 154: 726-40.

2 Starr A, Herr RH, Wood JA. Mitral replacement. f Thorac Cardiovasc Surg 1967; 54: 333-58.

3 Bonchek LI, Anderson RP, Starr A. Mitral valve replacement with cloth-covered composite-seat prostheses. The case for early operation. $f$ Thorac Cardiovasc Surg 1974; 67: 93-109.

4 Bjork VO. Results of mitral valve replacements with the Bjork-Shiley tilting disc valves. In: Kalmanson $\mathrm{D}$, ed. The mitral valve-a pluridisciplinary approach. London: Edward Arnold, 1976: 449-55.

5 Kirklin JW, Pacifico AD. Surgery for acquired valvular heart disease. (Second of two parts). $N$ Engl f Med 1973; 288: 194-9.

6 Kirklin JW. Replacement of the mitral valve for mitral incompetence. Surgery 1972; 72: 827-36.

7 Maloney JV Jr, Cooper N, Mulder DG, Buckberg GD. Depressed cardiac performance after mitral valve replacement. Circulation 1975; 51 \& 52, suppl I: 1-3, 1-8.

8 Mason SJ, Fortuin NJ. The use of echocardiography for quantitative evaluation of left ventricular function. Prog Cardiovasc Dis 1978; 21 : 119-32.

9 Feigenbaum H. Echocardiography. 2nd ed. Philadelphia: Lea \& Febiger, 1976.

10 Kreulen TH, Bove AA, McDonough MT, Sands MJ, Spann JF. The evaluation of left ventricular function in man: a comparison of methods. Circulation 1975; 51 : 677-88.

11 Grossman W, Brooks H, Meister S, Sherman H, 
Dexter L. New technique for determinating instantaneous myocardial force-velocity relations in the intact heart. Circ Res 1971; 28: 290-7.

12 Kolettis M, Jenkins BS, Webb-Peploe MM. Assessment of left ventricular function by indices derived from aortic flow velocity. $B r$ Heart $\mathcal{F} 1976$; 38: 18-31.

13 Snedecor GW, Cochran WG. Statistical methods. 6th ed. Ames, Iowa: Iowa State University Press, 1967: 258-98.

14 Urschel CW, Covell JW, Sonnenblick EH, Ross J Jr, Braunwald E. Myocardial mechanics in aortic and mitral valvular regurgitation: the concept of instantaneous impedance as a determinant of the performance of the intact heart. $\mathcal{F}$ Clin Invest 1968; 47: 867-83.

15 Sonnenblick EH. Implications of muscle mechanics in the heart. Fed Proc 1962; 21 : 975-90.

16 Ross J Jr, Sonnenblick EH, Taylor RR, Spotnitz HM, Covell JW. Diastolic geometry and sarcomere lengths in the chronically dilated canine left ventricle. Circ Res 1971; 28: 49-61.

17 Lewis BS, Gotsman MS. Left ventricular function during systole and diastole in mitral incompetence. Am f Cardiol 1974; 34: 635-43.

18 Schuler G, Peterson KL, Johnson A, et al. Temporal response of left ventricular performance to mitral valve surgery. Circulation $1979 ; 59$ : 1218-31.

19 Cohn PF, Gorlin R, Cohn LH, Collins JJ Jr. Left ventricular ejection fraction as a prognostic guide in surgical treatment of coronary and valvular heart disease. Am f Cardiol 1974; 34: 136-41.

20 Sonnenblick EH, Strobeck JE. Derived indexes of ventricular and myocardial function. $N$ Engl f $\mathrm{Med}$ 1977; 296: 978-82.

Requests for reprints to $\operatorname{Dr} M M$ Webb-Peploe, Department of Cardiology, St Thomas' Hospital, London SE1 7EH. 